\title{
Pediatrician Attitudes toward Digital Voice Assistant Technology Use in Clinical Practice
}

\author{
Jayme L. Wilder ${ }^{1,2}$ Devin Nadar ${ }^{3}$ Nitin Gujral ${ }^{3}$ Benjamin Ortiz ${ }^{4}$ Robert Stevens ${ }^{4}$ \\ Faye Holder-Niles ${ }^{1,2}$ John Lee ${ }^{2,5}$ Jonathan M. Gaffin ${ }^{2,6}$
}

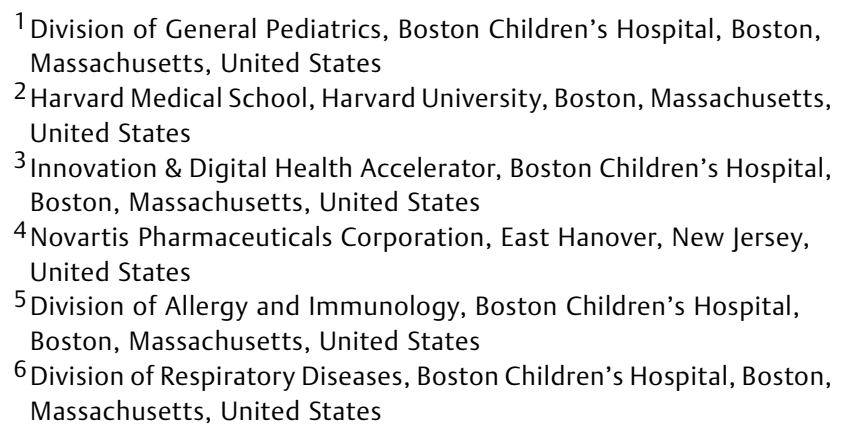

Address for correspondence Jonathan M. Gaffin, MD, MMSc, Division of Respiratory Diseases, Boston Children's Hospital, 300 Longwood Avenue, Boston, MA 02115, United States (e-mail: Jonathan.Gaffin@childrens.harvard.edu).

Appl Clin Inform 2019;10:286-294.

\begin{abstract}
Keywords

- mobile health

- human-computer interaction

- speech recognition software

- workflow

- pediatrics

Objective Digital voice assistant technology provides unique opportunities to enhance clinical practice. We aimed to understand factors influencing pediatric providers' current and potential use of this technology in clinical practice.

Methods We surveyed pediatric providers regarding current use and interest in voice technology in the workplace. Regression analyses evaluated provider characteristics associated with voice technology use. Among respondents not interested in voice technology, we elicited individual concerns.

Results Among 114 respondents, 19(16.7\%) indicated current use of voice technology in clinical practice, and 51 (44.7\%) indicated use of voice technology for nonclinical purposes. Fifty-four (47.4\%) reported willingness to try digital voice assistant technology in the clinical setting. Providers who had longer clinic visits (odds ratio [OR], 3.11, 95\% confidence interval $[\mathrm{Cl}], 1.04,9.33, p=0.04)$, fewer patient encounters per day $(p=0.02)$, and worked in hospital-based practices (OR, 2.95, 95\% Cl, 1.08, 8.07, $p=0.03$ ) were more likely to currently use voice technology in the office. Younger providers $(p=0.02)$ and those confident in the accuracy of voice technology $(\mathrm{OR}, 3.05,95 \% \mathrm{Cl}, 1.38,6.74, p=0.005$ ) were more willing to trial digital voice assistants in the clinical setting. Among respondents unwilling or unsure about trying voice assistant technology, the most common reasons elicited were concerns related to its accuracy (35\%), efficiency (33\%), and privacy (28\%). Conclusion This national survey evaluating use and attitudes toward digital voice assistant technology by pediatric providers found that while only one-eighth of pediatric providers currently use digital voice assistant technology in the clinical setting, almost half are interested in trying it in the future. Younger provider age and confidence in the accuracy of voice technology are associated with provider interest in using voice technology in the clinical setting. Future development of voice technology for clinical use will need to consider accuracy of information, efficiency of use, and patient privacy for successful integration into the workplace.
\end{abstract}

received

December 11, 2018

accepted after revision

March 17, 2019 (c) 2019 Georg Thieme Verlag KG

Stuttgart · New York
DOI https://doi.org/

10.1055/s-0039-1687863. ISSN 1869-0327. 


\section{Background and Significance}

Electronic health records (EHRs) have led to improvements in physician productivity, patient safety, and overall quality of care. ${ }^{1}$ However, EHRs have also led to a perceived increase in the administrative burden of physicians and have been associated with physician burnout. ${ }^{2,3}$ Improving the usability of an EHR, or the effectiveness and ease in which a user can complete a desired task, can help minimize these negative effects. ${ }^{4-6}$ The interface on which human-computer interaction takes place has typically been limited to a keyboard and mouse. However, new technologies, such as digital voice assistants, have broadened the ways that physicians can interact with EHRs, and have the potential to enhance usability, ultimately improving physician satisfaction and efficiency. ${ }^{7}$ Digital voice assistant technology is also an interface with which patients are familiar. If this new technology is integrated into the clinical setting, it has the potential to enhance EHR usability, improve physician satisfaction, and allow patients to more directly participate in their own care (-Fig. 1).

Digital voice assistant technology has emerged as an easyto-access platform available in people's homes, cars, and mobile devices. Digital voice assistants use speech recognition technology and natural language processing to execute users' voice commands to complete hands-free tasks and to find information. Amazon Alexa, Google Assistant, Apple's Siri, Microsoft Cortana, and Samsung's Bixby are the major commercial voice assistants currently available, making up $98 \%$ of the market share of the industry. ${ }^{8}$ Digital voice assistants are designed to help users complete a wide range of tasks, including playing music, sending messages, answering questions, managing home systems, and providing directions. These assistants exist on a variety of platforms including smartphones, computers, tablets, and standalone speakers, and are becoming ubiquitous in our society. A recent Pew Research report found that $46 \%$ of Americans regularly use digital voice assistants, ${ }^{9}$ and it is expected that by 2022 , voice-enabled smart speakers will be present in $55 \%$ of households in the United States. ${ }^{10}$

Modern digital voice assistant technology evolved from interactive voice response (IVR) systems. IVR technology allows users to interact with a computer-based system, typically over the telephone. These systems do not have as sophisticated natural language processing as digital voice assistants, and usually only recognize specific phrases or commands. IVR is often employed in call centers, but has been adapted to the healthcare setting. ${ }^{11}$

IVR technology was shown to improve adherence and decrease unplanned medical visits in adults with acute coronary syndrome after five automated telephone interactions with the technology over the course of 12 months. ${ }^{12}$ IVR can be used to provide and augment cognitive behavioral therapy (CBT); it was shown to be noninferior to in-person CBT in adults with chronic back pain, ${ }^{13}$ and to improve abstinence and coping skills in adults with alcoholism by reinforcing CBT concepts. ${ }^{14}$ In the pediatric population, IVR technology has been used to augment clinic visits to provide better counseling, medication management, and anticipatory guidance, leading to improved physician and parent satisfaction. ${ }^{15}$

However, IVR also has significant barriers to use, including patient refusal to answer phone calls, difficulty sorting background noise from voice responses, and a perceived dislike of the machine-like quality of the interaction. ${ }^{11}$ Additionally, IVR is limited by access through telephone calls. Subsequently, improvements in natural language processing and evolution to a variety of platforms that are readily accessible and

\begin{tabular}{|c|c|c|c|c|}
\hline & Education & Communication & Data Entry and Review & Other Assistive Functions \\
\hline 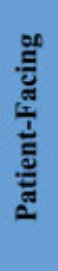 & $\begin{array}{l}\text { Answer questions regarding } \\
\text { disease state or medication } \\
\text { Access provider-selected } \\
\text { educational materials } \\
\text { on-demand }\end{array}$ & $\begin{array}{l}\text { Schedule appointments } \\
\text { Appointment reminders } \\
\text { Send adherence data } \\
\text { Communicate with provider }\end{array}$ & $\begin{array}{c}\text { Pre-populate forms } \\
\text { Review results }\end{array}$ & $\begin{array}{l}\text { Provide wait-times on } \\
\text { demand }\end{array}$ \\
\hline 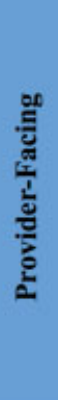 & $\begin{array}{l}\text { Access guidelines and } \\
\text { treatment plans } \\
\text { Review drug doses }\end{array}$ & $\begin{array}{l}\text { Communicate with patient } \\
\text { Send prescriptions, } \\
\text { notifications when obtained } \\
\text { Communicate with other } \\
\text { providers } \\
\text { Track adherence data } \\
\text { Create end-of-visit } \\
\text { instructions }\end{array}$ & $\begin{array}{l}\text { Review labs and imaging } \\
\text { Populate electronic health } \\
\text { record }\end{array}$ & Augment counseling \\
\hline & & & & $=$ requires HIPAA compliance \\
\hline
\end{tabular}

Fig. 1 Potential and current applications of digital voice assistant technology in healthcare. 
convenient have lead to the current form of digital voice assistant technology.

As digital voice assistants become more omnipresent, integration into the clinical setting has already begun. Several organizations have piloted digital voice assistant technology to better assist patients. Using voice technology, patients are able to check wait times at local emergency departments, schedule personal care assistants, receive adherence reminders, and ask basic logistical questions and call nurses in the in-patient setting. ${ }^{16}$ The intensive care unit at our home institution uses Amazon Alexa to provide staff information regarding patient assignments, capacity, and key policies and protocols.

Digital voice assistant technology provides unique opportunities for both patients and health care providers, and has only just begun to be explored. This technology has the capacity to improve both patients' and providers' access to educational materials, streamline communication, and augment workflow and efficiency. Digital voice assistants could reduce the amount of time physicians spend inputting data in the EHR, which could lead to improved efficiency and satisfaction, and leave more time for direct patient care. ${ }^{7,17}$ Additional potential uses are illustrated in - Fig. 1. However, providers' willingness to trial digital voice assistants in the clinical setting has yet to be studied.

\section{Objective}

To assess pediatric providers' interest in adopting digital voice assistant technology, we conducted a nationwide online survey (-supplementary Material, available in the online version). Our aim was to determine the prevalence of current digital voice technology use in the clinical setting and to better characterize physician attitudes toward future use of this technology, including obstacles to implementation. We anticipated that factors that may be prohibitive toward use of voice technology include confidence in the accuracy of responses, difficulties incorporating the technology into workflow, and limitations on time.

\section{Methods}

\section{Recruitment}

The online survey was programmed and distributed by MedPanel, Inc. From February 9, 2018 until March 2, 2018, the survey was distributed via email to all 23,000 pediatricians in MedPanel's database, spanning every U.S. state. Three email reminders were sent during this period.

\section{Survey Design}

The survey was generated by the investigators and in consultation with Boston Children's Hospital's Innovation \& Digital Health Accelerator. The survey contained 22 multiple-choice and open-ended questions addressing providers' practice characteristics, current use of technology, and willingness to try a digital voice assistant in clinical practice. Additionally, open-ended questions ascertained providers' concerns regarding use of voice technology, and elicited providers' suggestions for disease states best suited for use with this technology.

\section{Statistical Analysis}

Respondents were excluded from the analysis if primary outcome questions were not answered, or if greater than $50 \%$ of free-text responses were strings of random characters rather than words. Response choices to questions about frequency of technology use were ascertained on a scale of "none," "light," "moderate," and "heavy." Based on the distribution of these responses, these categories were combined into "none-light" and "moderate-heavy" to characterize type of use. Respondent characteristics were described using either means and standard deviations, or medians and interquartile ranges for continuous variables, and frequencies and percentiles for categorical variables.

Primary outcomes analyzed were current use of voice technology in the office, and willingness to try voice technology in the office. Providers' personal and practice characteristics were analyzed by univariate chi-squared analyses to determine factors influencing current and potential digital voice assistant use. Those characteristics with bivariate associations of $p<0.1$ were included in a multivariate regression analysis. For those respondents unsure or not willing to use voice technology in the clinical setting, individual concerns were elicited. All providers were asked to suggest disease states for which voice technology might be best suited. Open-ended questions were coded for qualitative analysis. Data analysis was performed using SPSS (IBM, New York, United States).

\section{Results}

\section{Provider Characteristics}

One hundred and ninety-two pediatric providers responded to the survey, a response rate of $0.8 \%$. Of these, 111 (58\%) surveys were completed in full, and 81 (42\%) were partially completed. One hundred and fourteen respondents with primary outcome data were included in the final analysis.

Respondents' practice characteristics are noted in -Table 1. The average age of respondents was 53.1 years (standard deviation [SD] 10.2). Respondents primarily worked in office-based practices (68\%) and in practices with fewer than 20 providers (83\%). Twenty-eight (25\%) providers identified as pediatric subspecialists. Providers saw on average 22.8 (SD 10.8) patients per day, and an estimated $41 \%$ (SD $28 \%$ ) of these patients utilize public health insurance. The vast majority of respondents describe themselves as moderate to heavy users of technology both at home (82\%) and in the office (88\%) (-Table 2 ).

Practice and technology use characteristics among the 78 providers who were not included in the final analysis due to incomplete surveys were similar to the included group (-Tables 1 and 2). Excluded respondents tended to work in small practices compared with the included group (51\% vs. $40 \%$ ), and to have small patient panels (65\% vs. $55 \%$ ). Excluded respondents estimated that their patients' parents had less education, with $20 \%$ having less than a high school diploma, compared with $10 \%$ of the included group. None of these 
Table 1 Provider characteristics of included and excluded respondents

\begin{tabular}{|c|c|c|}
\hline & \multicolumn{2}{|c|}{$\begin{array}{l}\text { Number of respondents } \\
\text { (\%), except where noted }\end{array}$} \\
\hline & $\begin{array}{l}\text { Included } \\
\text { providers }\end{array}$ & $\begin{array}{l}\text { Excluded } \\
\text { providers }\end{array}$ \\
\hline \multicolumn{3}{|l|}{ Practice } \\
\hline Hospital based & $36(32)$ & $27(38)$ \\
\hline Office based & $78(68)$ & $44(62)$ \\
\hline \multicolumn{3}{|l|}{ Practice size } \\
\hline Small (1-5 providers) & $46(40)$ & $34(51)$ \\
\hline Medium (6-20 providers) & $49(43)$ & $24(36)$ \\
\hline Large ( $>20$ providers) & $19(17)$ & $9(13)$ \\
\hline \multicolumn{3}{|l|}{ Patient panel size } \\
\hline Small ( $<1,900$ patients) & $63(55)$ & $40(65)$ \\
\hline Large ( $>1,900$ patients) & $51(45)$ & $22(35)$ \\
\hline $\begin{array}{l}\text { Patient volume, daily, } \\
\text { mean (SD) }\end{array}$ & $22.8(10.8)$ & $20.1(8.5)$ \\
\hline \multicolumn{3}{|l|}{$\begin{array}{l}\text { Time allotted per } \\
\text { patient visit }\end{array}$} \\
\hline$<15$ minutes & $55(48)$ & $24(49)$ \\
\hline$\geq 15$ minutes & $59(52)$ & $36(51)$ \\
\hline $\begin{array}{l}\text { Patients using public } \\
\text { health insurance, \% (SD) }\end{array}$ & $41(28)$ & $43(31)$ \\
\hline \multicolumn{3}{|l|}{$\begin{array}{l}\text { Parent education } \\
\text { median \% (25th, 75th) }\end{array}$} \\
\hline $\begin{array}{l}\text { Less than high } \\
\text { school diploma }\end{array}$ & $10(5,20)$ & $20(5,25)$ \\
\hline $\begin{array}{l}\text { Bachelor degree } \\
\text { or higher }\end{array}$ & $30(15,45)$ & $31(10,50)$ \\
\hline \multicolumn{3}{|l|}{ Type of provider } \\
\hline Specialist & $28(25)$ & No data \\
\hline Generalist & $86(75)$ & No data \\
\hline
\end{tabular}

Abbreviation: SD, standard deviation.

excluded respondents completed the primary outcome questions.

\section{Digital Voice Assistant Technology: Current and Future Use}

Among the 114 respondents, 19 (16.7\%) indicated current use of voice technology in the office, 51 (44.7\%) use voice technology outside of the office, and 44 (38.6\%) were nonusers of voice technology. Fifty-four (47.4\%) reported willingness to try a voice assistant in the clinical setting ( - Table 2 ). In univariate analysis, those who spent a greater amount of time on clinical visits (odds ratio [OR] 3.11, 95\% confidence interval [CI], 1.04, $9.33, p=0.04)$, and those working in hospital-based practices (OR, 2.95, 95\% CI, 1.08, 8.07, $p=0.03$ ), were more likely to use voice technology in the office. Those seeing more patients per day were less likely to use voice technology in the office (OR, $0.93,95 \% \mathrm{CI}, 0.87,0.99, p=0.02$ ). Specialists tended to be more
Table 2 Respondents' use of technology and comparison to excluded providers

\begin{tabular}{|c|c|c|}
\hline \multirow[b]{2}{*}{$\begin{array}{l}\text { General technology } \\
\text { use characteristics }\end{array}$} & \multicolumn{2}{|c|}{$\begin{array}{l}\text { Number of respondents } \\
\text { (\%), except where noted }\end{array}$} \\
\hline & $\begin{array}{l}\text { Included } \\
\text { providers }\end{array}$ & $\begin{array}{l}\text { Excluded } \\
\text { providers }\end{array}$ \\
\hline \multicolumn{3}{|l|}{ At home } \\
\hline Non- to light user & $20(18)$ & $10(23)$ \\
\hline Moderate to heavy user & $94(82)$ & $33(77)$ \\
\hline \multicolumn{3}{|l|}{ In the office } \\
\hline Non- to light user & $14(12)$ & $4(9)$ \\
\hline Moderate to heavy user & $100(88)$ & $39(90)$ \\
\hline \multicolumn{3}{|l|}{$\begin{array}{l}\text { Likely to recommend new } \\
\text { technology in the office }\end{array}$} \\
\hline Likely & $71(62)$ & $29(69)$ \\
\hline Unlikely & $43(38)$ & $13(31)$ \\
\hline \multicolumn{3}{|l|}{ User of dictation software } \\
\hline Yes & $28(25)$ & No data \\
\hline No & $86(75)$ & No data \\
\hline \multicolumn{3}{|l|}{$\begin{array}{l}\text { Voice technology } \\
\text { use characteristics }\end{array}$} \\
\hline \multicolumn{3}{|l|}{$\begin{array}{l}\text { Location of current } \\
\text { voice technology use }\end{array}$} \\
\hline Office user & $19(16.7)$ & No data \\
\hline Nonoffice user & $51(44.7)$ & No data \\
\hline Nonuser & $44(38.6)$ & No data \\
\hline \multicolumn{3}{|l|}{$\begin{array}{l}\text { Interest in using voice in } \\
\text { clinical setting }\end{array}$} \\
\hline Yes & $54(47.4)$ & No data \\
\hline Maybe & $40(35.1)$ & No data \\
\hline No & $20(17.5)$ & No data \\
\hline \multicolumn{3}{|l|}{$\begin{array}{l}\text { Confident in answers from } \\
\text { voice technology }\end{array}$} \\
\hline Confident & $69(60.5)$ & No data \\
\hline Not confident & $45(39.5)$ & No data \\
\hline
\end{tabular}

likely to use voice technology compared with nonspecialists, though this was not statistically significant (OR, 2.73, 95\% CI, 0.97, 7.68, $p=0.052$ ) (-Table 3). No individual factor was independently associated with current use of voice technology when clinic visit time, practice location, number of patients, and specialist determinants were included in the same multivariate model.

Univariate analysis was also performed to determine which provider characteristics were associated with willingness to try voice technology in the clinical setting ( - Table 4). Providers who were confident in the answers provided by voice technology were more willing to try this technology (OR, 3.05, $95 \% \mathrm{CI}, 1.38,6.74, p=0.005)$. Younger providers were also more likely to be willing to try voice technology $(p=0.02)$. Both confidence in voice technology $(p=0.013)$ and age of $\operatorname{provider}(p=0.041)$ remained independently associated with 
Table 3 Univariate and multivariate associations of provider characteristics with current use of voice technology in the office

\begin{tabular}{|c|c|c|c|c|c|c|}
\hline \multirow[t]{2}{*}{ Variable } & \multicolumn{3}{|l|}{ Univariate } & \multicolumn{3}{|l|}{ Multivariate } \\
\hline & Odds ratio & $95 \% \mathrm{Cl}$ & $p$-Value & Odds ratio & $95 \% \mathrm{Cl}$ & $p$-Value \\
\hline \multicolumn{7}{|l|}{$\begin{array}{l}\text { Number of providers in practice } \\
\text { (reference: }>20 \text { providers) }\end{array}$} \\
\hline $1-5$ providers & 1.66 & $0.32,8.63$ & \multirow[t]{2}{*}{0.67} & & & \\
\hline $6-20$ providers & 2.07 & $0.30,10.62$ & & & & \\
\hline $\begin{array}{l}\text { Patient panel }>1,900 \text { patients } \\
\text { (reference: }<1,900 \text { patients) }\end{array}$ & 1.46 & $0.55,3.93$ & 0.45 & & & \\
\hline $\begin{array}{l}>15 \text { minute per patient encounter } \\
\text { (reference: }<15 \text { minute per encounter) }\end{array}$ & 3.11 & $1.04,9.33$ & 0.04 & 1.57 & $0.42,5.96$ & 0.5 \\
\hline $\begin{array}{l}\text { Moderate-heavy use of technology at } \\
\text { home (reference: no-light use) }\end{array}$ & 1.99 & $0.42,9.38$ & 0.38 & & & \\
\hline $\begin{array}{l}\text { Hospital-based practice } \\
\text { (reference: office-based practice) }\end{array}$ & 2.95 & $1.08,8.07$ & 0.03 & 1.38 & $0.35,5.38$ & 0.64 \\
\hline Confidence in voice technology answers & 2.04 & $0.68,6.11$ & 0.2 & & & \\
\hline Age & 0.96 & $0.92,1.01$ & 0.14 & & & \\
\hline Percent patient on public insurance & 1.01 & $0.997,1.03$ & 0.104 & & & \\
\hline Number of patients per day & 0.93 & $0.87,0.99$ & 0.02 & 0.95 & $0.88,1.04$ & 0.27 \\
\hline Specialist (reference: generalist) & 2.73 & $0.97,7.68$ & 0.052 & 1.6 & $0.45,5.71$ & 0.47 \\
\hline
\end{tabular}

Abbreviation: $\mathrm{Cl}$, confidence interval.

Table 4 Univariate and multivariate associations of provider characteristics with willingness to try voice technology in the clinical setting

\begin{tabular}{|c|c|c|c|c|c|c|}
\hline \multirow[t]{2}{*}{ Variable } & \multicolumn{3}{|l|}{ Univariate } & \multicolumn{3}{|l|}{ Multivariate } \\
\hline & Odds ratio & $95 \% \mathrm{Cl}$ & $p$-Value & Odds ratio & $95 \% \mathrm{Cl}$ & $p$-Value \\
\hline \multicolumn{7}{|l|}{$\begin{array}{l}\text { Number of providers in practice } \\
\text { (reference: }>20 \text { providers) }\end{array}$} \\
\hline $1-5$ providers & 1.5 & $0.51,4.41$ & 0.69 & & & \\
\hline $6-20$ providers & 1.12 & $0.38,3.27$ & & & & \\
\hline $\begin{array}{l}\text { Patient panel }>1,900 \text { patients } \\
\text { (reference: }<1,900 \text { patients) }\end{array}$ & 0.74 & $0.35,1.54$ & 0.42 & & & \\
\hline $\begin{array}{l}>15 \text { minute per patient encounter } \\
\text { (reference: }<15 \text { minute per encounter) }\end{array}$ & 1.54 & $0.74,3.23$ & 0.25 & & & \\
\hline $\begin{array}{l}\text { Moderate-heavy use of technology } \\
\text { at home (reference: no-light use) }\end{array}$ & 0.88 & $0.34,2.31$ & 0.8 & & & \\
\hline $\begin{array}{l}\text { Moderate-heavy use of technology } \\
\text { in office (reference: no-light use) }\end{array}$ & 1.73 & $0.54,5.52$ & 0.35 & & & \\
\hline $\begin{array}{l}\text { Hospital-based practice } \\
\text { (reference: office-based practice) }\end{array}$ & 1.91 & $0.86,4.25$ & 0.11 & & & \\
\hline Confidence in voice technology answers & 3.05 & $1.38,6.74$ & 0.005 & 2.86 & $1.25,6.54$ & 0.013 \\
\hline Age & 0.96 & $0.92,0.995$ & 0.02 & 0.96 & $0.92,0.998$ & 0.041 \\
\hline Percent patient on public insurance & 1.01 & $0.99,1.02$ & 0.48 & & & \\
\hline Number of patients per day & 1 & $0.96,1.03$ & 0.78 & & & \\
\hline Specialist (reference: generalist) & 1.15 & $0.49,2.7$ & 0.75 & & & \\
\hline
\end{tabular}

Abbreviation: $\mathrm{Cl}$, confidence interval. 
Table 5 Use of commercially available digital voice assistants by pediatricians who currently use voice technology in the office

\begin{tabular}{|l|l|l|l|l|}
\hline & \multicolumn{4}{|l|}{ Number of respondents (\% of office users) } \\
\hline & $\begin{array}{l}\text { Amazon } \\
\text { Alexa }\end{array}$ & $\begin{array}{l}\text { Google } \\
\text { Home }\end{array}$ & $\begin{array}{l}\text { Apple's } \\
\text { Siri }\end{array}$ & $\begin{array}{l}\text { Microsoft } \\
\text { Cortana }\end{array}$ \\
\hline Use often & $3(16)$ & $3(16)$ & $8(42)$ & $0(0)$ \\
\hline Use rarely & $4(21)$ & $2(11)$ & $6(32)$ & $6(32)$ \\
\hline Never use & $12(63)$ & $14(74)$ & $5(26)$ & $13(68)$ \\
\hline
\end{tabular}

willingness to try voice technology in the clinical setting in the multivariate model.

Providers were asked about their frequency of use of specific commercially available digital voice assistants in all settings. Of the 19 providers who indicated use of digital voice assistant technology in the office, Apple's Siri was the most frequently used ( - Table 5 ), although this result is not specific to office use.

\section{Concerns Regarding Voice Technology}

Respondents were asked in an open-ended question why they were unwilling or unsure about trying voice assistant technology in the clinical setting. These responses were coded into several categories, and are listed in -Table 6. The most commonly cited concerns were accuracy of answers provided (35\%), efficiency of use in the clinic (33\%), and privacy (28\%).

\section{Pediatric Diseases Best Suited to Voice Technology}

Respondents were asked which disease states may be best suited to voice assistant technology. These responses were coded into several categories. Of those that listed a disease

Table 6 Concerns cited for unwillingness to try voice technology in the clinical setting

\begin{tabular}{|l|l|}
\hline & Number of respondents (\%) \\
\hline Accuracy & $21(35)$ \\
\hline Efficiency & $20(33)$ \\
\hline Privacy & $17(28)$ \\
\hline Utility & $9(15)$ \\
\hline Misinterpretation & $7(12)$ \\
\hline Noise & $4(7)$ \\
\hline Other & $2(3)$ \\
\hline
\end{tabular}

Table 7 Disease states best suited for voice assistant technology

\begin{tabular}{|l|l|}
\hline & Number of respondents (\%) \\
\hline Asthma & $33(29)$ \\
\hline Diabetes & $22(19)$ \\
\hline Psychiatric/behavior & $14(12)$ \\
\hline Nutrition & $9(8)$ \\
\hline Development & $9(8)$ \\
\hline Viral symptoms & $7(6)$ \\
\hline
\end{tabular}

state, asthma (29\%), diabetes (19\%), and behavioral/psychiatric disorders (12\%) were the most common responses (- Table 7 ).

\section{Discussion}

\section{Principal Results and Future Development}

This national survey evaluating use and attitudes toward digital voice assistant technology by pediatric providers indicates that while only one-eighth of providers currently use a form of voice technology in the clinical setting, almost half would be interested in trying it in the future. This study is the first to elucidate characteristics associated with use of this emerging technology in clinical practice.

We found that providers who currently use voice technology in the clinical setting primarily work in hospitalbased practices, see fewer patients per day, and spend more time on each patient visit. This combination of characteristics suggests that these providers likely work in academic practices that afford them more time to trial new technologies, such as digital voice assistants. Given that efficiency was a key concern for many respondents unwilling to try voice technology (33\%), providers with busier schedules may be less likely to currently have voice technology in the office.

Confidence in the information provided by the technology was the most important factor in willingness to try voice assistant technology in clinical practice. Younger age of provider was also associated with willingness to try voice technology. Given that accuracy was the number one concern among providers unsure or unwilling to try voice technology (35\%), it is not surprising that those who have more confidence in the reliability of voice technology answers would be more willing to try it.

Similar to its predecessor, IVR, digital voice assistants have the power to augment clinical visits by populating forms, reviewing and sending prescriptions, tracking adherence and clinical markers, and augmenting physician counseling (-Fig. 1). Digital voice assistants could be a powerful educational tool for both patients and providers; providers could quickly access clinical information, guidelines, and medication doses in the exam room using hands-free technology, and patients could access educational material while waiting for a provider, and could further review these materials on their own devices at home. Furthermore, digital voice assistants could enhance the usability of EHRs, minimizing the time required for physicians to populate the patient's record, and ultimately leading to improved physician efficiency and satisfaction.

However, many of these applications require compliance with the Health Insurance Portability and Accountability Act (HIPAA). None of the major commercial digital voice assistants are currently HIPAA compliant, although developers are in the process of remedying this. ${ }^{18}$ This limits their current use to nonpatient-specific educational materials and administrative tasks, and prevents direct interaction with the EHR. Developers of EHRs have begun creating their own digital voice assistants, but these can only be accessed by healthcare providers in the EHR, and do not provide patient-facing services. ${ }^{19}$ Nonetheless, patients could still benefit from EHR-specific digital voice 
assistants, as improved physician efficiency from this new interface could lead to more time for patient care.

Regardless of whether commercial digital voice assistants become HIPAA compliant, or if EHR-specific voice assistants become more prevalent, the technology currently exists to make the many possible benefits of healthcare-integrated digital voice assistants a reality; yet, content still needs to be developed and devices need to be trialed. This study, the first to examine pediatricians' interest in the technology, provides an important perspective to content and device developers as this technology begins to enter the clinical space. This study showed that accuracy of voice technology responses is the most crucial factor in adoption into the clinical workspace. Those providers who were confident in voice technology answers were more willing to trial it, and among those unwilling to try, accuracy was cited as the number one concern. This concern is valid; A 2018 study by Boyd and Wilson examined the quality and accuracy of digital voice assistant technology responses related to smoking cessation advice. The accuracy of responses ranged from 28 to $76 \%{ }^{20}$ Additionally, digital voice assistants were found to respond to queries and statements about mental health, physical health, and interpersonal violence inconsistently, and at times, inappropriately. ${ }^{21}$ Given this, it will be critical for developers to focus on the accuracy of information provided by the devices when used for clinical purposes. Additional concerns raised by providers included efficiency and privacy; these too will need to be addressed before more wide-spread clinical adoption is possible.

With regards to which disease states could be best served by digital voice assistants, the top three responses by providers queried in this study were asthma, diabetes, and psychiatric/behavioral disorders (such as attention deficit hyperactivity disorder and depression). These diseases are all chronic and require frequent monitoring and education. Many standardized approaches to management of these diseases already exist, such as the National Heart, Lung, and Blood Institute guidelines, ${ }^{22}$ and additionally, standardized educational materials, such as Asthma Action Plans, are already commonly distributed to patients. This standardized approach lends itself well to digital voice assistants, as guidelines and educational materials can be incorporated into the technology with relative ease and accuracy. Similar to the Adams et al study in 2014, in which patients used IVR to prepopulate visit questionnaires and express concerns, digital voice assistant technology could be used to closely monitor chronic disease states and provide more frequent, effective, and targeted provider-patient interactions. ${ }^{15}$

\section{Limitations}

We recognize that the low response rate to the nationwide survey may limit the generalizability of our findings and that providers that respond to online surveys may be more frequent users of technology, and therefore more likely to use or trial digital voice technology. Sixty-one percent of respondents have used digital voice technology at home or in the office, compared with $44 \%$ of Americans as reported by the Pew Research report. ${ }^{9}$ However, it is likely that physi- cians may be higher users of technology at baseline compared with the general population due to higher overall education and requirement to interact with electronic technology for work and training, and that this cohort of respondents may be similar to those studies with a more robust response. Additionally, the diverse representation of respondents across specialty and general pediatric practices in both hospital- and office-based settings, suggests that these findings may be representative of the diversity of opinion among pediatric providers. Free-response questions were coded using qualitative research methods, but these may not have adequately captured the providers' responses. However, given the lack of standardized survey methodology in this field, we feel that using free-response questions strengthened this research by allowing unrestricted responses to attitudes surrounding voice technology.

We did not specifically ask how providers use digital voice assistant technology in the office, as our objective was to broadly characterize use and interest in integration into the clinical setting. We recognize that it is possible providers use commercial voice assistants for personal, rather than clinical, tasks while at work. However, recently published reports show that voice assistants are being used for clinical tasks, and work is ongoing to broaden their functions and availability in healthcare. ${ }^{16,18,19}$ Additionally, we asked a freeresponse question eliciting when providers enjoyed using digital voice assistants. We did not have enough responses to this question to qualitatively analyze the data, but responses included "online searching," "dictating emails/texts," and "ICD10 [International Classification of Diseases, 10th Revision] searches," which suggests that our respondents are using voice assistants for clinical functions.

Providers identified several disease states that might be best suited for digital voice assistant technology use. While we hypothesize that providers believe chronic diseases and diseases with standardized guidelines would be best suited for voice technology, this question was not specifically asked. As educational and administrative functions are designed for digital voice assistants with specific disease states in mind, this area should be further studied to optimize both patient care and physician need.

In light of the limitations noted here, it will be important to replicate these findings across other providers groups and across a broad range of personal and practice demographics to best understand the general applicability of digital voice technology. It is likely that needs assessments and utilization patterns will vary depending on the practice style and adaptability to the clinical workflow. Furthermore, studies in which introduction of actual devices that generate direct feedback from key stakeholders, both physicians and patients alike, will be important to ultimately optimizing the use of this technology in the clinical setting.

\section{Conclusion}

This national survey evaluating use and attitudes toward digital voice assistant technology by pediatric providers found that while only $16.7 \%$ of pediatric providers currently 
use digital voice assistant technology in the clinical setting, $47.4 \%$ are interested in trying it in the future. Younger provider age and confidence in the accuracy of voice technology are associated with provider interest in using voice technology in the clinical setting. Pediatricians who are not interested or unsure about trying voice technology in the clinical setting cited concerns related to accuracy of information, privacy, and efficiency of use. As digital voice assistant technology becomes more omnipresent, its adoption into the clinical workplace is inevitable. For integration in the healthcare setting to be successful, developers will need to consider the provider characteristics elucidated in this study.

\section{Clinical Relevance Statement}

Digital voice assistants are becoming a more popular and accessible form of technology in our society, and could potentially be used to augment clinical visits and to educate both patients and providers. As this technology begins to enter clinical settings, awareness of physician interest and concerns will be crucial in its successful integration.

\section{Multiple Choice Questions}

1. Interactive voice response systems (IVR), precursors to digital voice assistant technologies, have been shown in the medical literature to have which of the following positive effects?

a. Improve medication adherence.

b. Decrease unplanned medical visits.

c. Improve physician satisfaction.

d. All of the above.

Correct Answer: The correct answer is option d. IVR was shown to improve medication compliance, decrease adverse events, and decrease unplanned medical visits over the course of 12 months in patients who had an acute coronary syndrome. ${ }^{12}$ Additionally, IVR was shown to improve both patient and physician satisfaction in a study assessing its use in pediatric primary care. ${ }^{15}$

2. On what types of digital platforms do voice assistant technologies currently exist?
a. Mobile phones.
b. Smart speakers.
c. Computers.
d. All of the above.

Correct Answer: The correct answer is option d. Digital voice assistants are currently available on computers, tablets, mobile phones, smart speakers, smart watches, and cars. As this technology continues to become more widely available, its migration into the clinical setting is inevitable.

\section{Protection of Human and Animal Subjects}

This study was reviewed by the Boston Children's Hospital Institutional Review Board (IRB), and was deemed exempt from IRB oversight.

\section{Funding}

This study was supported by NIH grants K23AI106945 and R01 ES030100 (PI: J.M.G.).

\section{Conflict of Interest}

None declared.

\section{Acknowledgments}

MedPanel, Inc. (Cambridge, Massachusetts, United States) programmed and distributed the physician survey used in this research free of charge. MedPanel was not involved in the analysis of the data or development of the manuscript. The study was supported by Novartis Pharmaceuticals (Basel, Switzerland). The data collection, analysis plan, data analysis, and editorial process were performed by the researchers at Boston Children's Hospital with input, but not oversight, from the collaborators at Novartis. The corresponding author had final editorial control over the manuscript.

\section{References}

1 Jones SS, Rudin RS, Perry T, Shekelle PG. Health information technology: an updated systematic review with a focus on meaningful use. Ann Intern Med 2014;160(01):48-54

2 Shanafelt TD, Dyrbye LN, Sinsky C, et al. Relationship between clerical burden and characteristics of the electronic environment with physician burnout and professional satisfaction. Mayo Clin Proc 2016;91(07):836-848

3 Jamoom EW, Heisey-Grove D, Yang N, Scanlon P. Physician opinions about EHR use by EHR experience and by whether the practice had optimized its EHR use. J Health Med Inform 2016;7(04):1000240

4 Middleton B, Bloomrosen M, Dente MA, et al; American Medical Informatics Association. Enhancing patient safety and quality of care by improving the usability of electronic health record systems: recommendations from AMIA. J Am Med Inform Assoc 2013;20(e1):e2-e8

5 Ratwani R, Fairbanks T, Savage E, et al. Mind the gap. A systematic review to identify usability and safety challenges and practices during electronic health record implementation. Appl Clin Inform 2016;7(04):1069-1087

6 Wilbanks BA, Moss J. Evidence-based guidelines for interface design for data entry in electronic health records. Comput Inform Nurs 2018;36(01):35-44

7 Collier R. Rethinking EHR interfaces to reduce click fatigue and physician burnout. CMAJ 2018;190(33):E994-E995

8 Wagner P. Siri remains the most used mobile voice assistant. Statista; June 29, 2018. Available at: https://www.statista.com/ chart/14505/market-share-of-voice-assistants-in-the-us. Accessed January 1, 2019

9 Olmstead K. Nearly half of Americans use digital voice assistants, mostly on their smartphones. Washington, DC: Pew Research Center; December 12, 2017. Available at: http://www.pewresearch.org/fact-tank/2017/12/12/nearly-half-of-americans-usedigital-voice-assistants-mostly-on-their-smartphones. Accessed August 7, 2018

10 Amazon Echo \& Google Home to reside in over $50 \%$ of US households by 2022 as multi-assistant devices take off. Hampshire, UK: Juniper Research; November 8, 2017. Available at: https://www. juniperresearch.com/press/press-releases/amazon-echo-googlehome-to-reside. Accessed August 7, 2018

11 Kumah-Crystal YA, Pirtle CJ, Whyte HM, Goode ES, Anders SH, Lehmann CU. Electronic health record interactions through voice: a review. Appl Clin Inform 2018;9(03):541-552 
12 Sherrard H, Duchesne L, Wells G, Kearns SA, Struthers C. Using interactive voice response to improve disease management and compliance with acute coronary syndrome best practice guidelines: a randomized controlled trial. Can J Cardiovasc Nurs 2015; 25(01):10-15

13 Heapy AA, Higgins DM, Goulet JL, et al. Interactive voice responsebased self-management for chronic back pain: the COPES Noninferiority Randomized Trial. JAMA Intern Med 2017;177(06): 765-773

14 Rose GL, Skelly JM, Badger GJ, Naylor MR, Helzer JE. Interactive voice response for relapse prevention following cognitive-behavioral therapy for alcohol use disorders: a pilot study. Psychol Serv 2012;9(02):174-184

15 Adams WG, Phillips BD, Bacic JD, Walsh KE, Shanahan CW, Paasche-Orlow MK. Automated conversation system before pediatric primary care visits: a randomized trial. Pediatrics 2014;134(03):e691-e699

16 Siwicki B. Special Report: AI voice assistants making an impact in healthcare. Healthcare IT News. February 1, 2018. Available at: https://www.healthcareitnews.com/news/special-report-aivoice-assistants-making-impact-healthcare. Accessed January 1 , 2019
17 Hill RG Jr, Sears LM, Melanson SW. 4000 clicks: a productivity analysis of electronic medical records in a community hospital ED. Am J Emerg Med 2013;31(11):1591-1594

18 Donovan F. Amazon's Alexa healthcare team bones up on HIPAA compliance. Health IT Security. May 14, 2018. Available at: https://healthitsecurity.com/news/amazons-alexa-healthcareteam-bones-up-on-hipaa-compliance. Accessed January 1, 2019

19 McCluskey PD. Meet Eva, the voice-activated 'assistant' for doctors. Boston Globe;January 9, 2018. Available at: https://www. bostonglobe.com/business/2018/01/09/meet-eva-voice-activated-assistant-for-doctors/uvvvtEvOu8R3SC2AhIC8xI/story. html. Accessed January 1, 2019

20 Boyd M, Wilson N. Just ask Siri? A pilot study comparing smartphone digital assistants and laptop Google searches for smoking cessation advice. PLoS One 2018;13(03):e0194811

21 Miner AS, Milstein A, Schueller S, Hegde R, Mangurian C, Linos E. Smartphone-based conversational agents and responses to questions about mental health, interpersonal violence, and physical health. JAMA Intern Med 2016;176(05):619-625

22 National Heart, Lung, and Blood Institute. National Asthma Education and Prevention Program. Expert Panel Report 3: Guidelines for the Diagnosis and Management of Asthma; 2007 